\title{
Genetics and epigenetics of liver cancer
}

\section{Cigdem Ozen ${ }^{1}$, Gokhan Yildiz ${ }^{1,2}$, Alper Tunga Dagcan ${ }^{1}$, Dilek Cevik ${ }^{1,2}$, Aysegul Ors ${ }^{1,2}$, Umur Keles ${ }^{1}$, Hande Topel ${ }^{1}$ and Mehmet Ozturk ${ }^{1,2}$}

\footnotetext{
${ }^{1}$ Bilkent University, BilGen Genetics and Biotechnology Center, Department of Molecular Biology and Genetics, 06800 Ankara, Turkey

${ }^{2}$ Université Joseph Fourier - Grenoble 1, INSERM Institut Albert Bonniot, U823, Site Santé-BP 170, 38042 Grenoble Cedex 9, France
}

Hepatocellular carcinoma (HCC) represents a major form of primary liver cancer in adults. Chronic infections with hepatitis $\mathrm{B}(\mathrm{HBV})$ and $\mathrm{C}(\mathrm{HCV})$ viruses and alcohol abuse are the major factors leading to HCC. This deadly cancer affects more than 500,000 people worldwide and it is quite resistant to conventional chemo- and radiotherapy. Genetic and epigenetic studies on HCC may help to understand better its mechanisms and provide new tools for early diagnosis and therapy. Recent literature on whole genome analysis of HCC indicated a high number of mutated genes in addition to well-known genes such as TP53, CTNNB1, AXIN1 and CDKN2A, but their frequencies are much lower. Apart from CTNNB1 mutations, most of the other mutations appear to result in loss-of-function. Thus, HCC-associated mutations cannot be easily targeted for therapy. Epigenetic aberrations that appear to occur quite frequently may serve as new targets. Global DNA hypomethylation, promoter methylation, aberrant expression of non-coding RNAs and dysregulated expression of other epigenetic regulatory genes such as $E Z H 2$ are the best-known epigenetic abnormalities. Future research in this direction may help to identify novel biomarkers and therapeutic targets for HCC.

\section{Introduction}

The most frequent primary liver cancers are hepatocellular carcinoma (HCC) and cholangiocarcinoma in adults, and hepatoblastoma in children. More than $80 \%$ of liver tumours are HCCs [1]. This review will focus primarily on HCC, one of the most frequent cancers worldwide with more than 500,000 new cases observed each year. Almost the same number of deaths is observed because of this cancer could not be easily treated. The most efficient treatment for HCC is liver transplantation, provided that it is detected early enough. Surgical removal and chemo-embolisation of tumour nodules are other alternatives. These tumours are usually resistant to chemo- or radiotherapy [1-3]. Targeted therapy of HCC is in its infancy. The only clinically relevant drug is a kinase inhibitor, Sorafenib, has only a modest effect on patient survival [4].

The aetiology of HCC is well known. Chronic liver injury associated primarily with hepatitis $\mathrm{B}(\mathrm{HBV})$ and $\mathrm{C}(\mathrm{HCV})$ virus infection constitutes the most important cause of HCC. Other factors, such as alcohol abuse and dietary exposure to aflatoxins, are also established causes, but their contribution to the disease aetiology is much less than the contributions of viral agents. The unprecedented increase in obesity rates in both developed and developing countries is a rising concern for HCC risk that may account for the unexpected increase in HCC incidence in the Western world [1].

Molecular mechanisms of hepatocellular carcinogenesis remain ill-defined, mainly due to disease heterogeneity. The heterogeneity of agents that cause chronic liver injury (HBV, HCV, aflatoxins and alcohol) and the ways they interact with the host DNA and epigenetic players are the most probable parameters contributing to HCC heterogeneity.

\section{Chromosomal aberrations and hepatitis B virus integration into the host genome}

Chromosomal aberrations such as deletions and copy number gains are frequent in HCC. Initial studies identified that HCC 
harbours multiple chromosomal abnormalities, predominantly losses, with increased chromosomal instability in tumours associated with HBV infection. Common alterations include gain of chromosomes 1q, 8q and 17q, and loss of 4q [5]. Recently, data from whole genome analysis techniques showed that chromosomes $1 \mathrm{q}, 5,6 \mathrm{p}, 7,8 \mathrm{q}, 17 \mathrm{q}$ and 20 display chromosomal gains, while $1 p, 4 q, 6 q, 8 p, 13 q, 16,17 p$ and 21 exhibit losses in HCC [6].

In addition, HBV DNA is often integrated into the host genome in patients with HBV-related HCCs [7]. This integration may have cis and trans effects. Viral DNA integration into or near gene sequences may alter gene expression as well as gene integrity. In addition, integrated viral DNA may encode wild-type or truncated viral proteins acting in trans on the host genome, either by deregulating gene expression or by interacting with host proteins [8]. Recently reported whole genome studies indicated that the viral integration is associated with breakpoints within the HBV genome that primarily localised to the downstream region of the $H B X$ gene. HBV genome integration was observed within or upstream of the TERT (telomerase reverse transcriptase) gene in four HBV-related HCCs. However, HBV integration sites within the same or different tumours did not show specific patterns, suggesting that the virus does not target specific host sequences. [9]. Based on these findings, it is highly probable that landscape changes in the structural integrity of chromosomes, as well as random but multiple integrations of HBV genomes into host genomes, cause high levels of instability in the chromosomal integrity of HCC. Some of these aberrations may hit crucial genes such as TERT, which may directly contribute to tumour development by inappropriate activation or inactivation of the genes themselves. In addition, the integration of viral enhancer sequences in the vicinity of crucial genes may lead to aberrant gene expression in HCC.

\section{Gene mutations}

Since the discovery of TP53 as the first mutated gene in HCC over 20 years ago [10] and until very recently, only four genes were known to display frequent alterations in liver cancers. While TP53, CTNNB1 (encoding $\beta$-catenin) and $A X I N 1$ genes usually display point mutations and small deletions, CDKN2A (encoding p $16^{\mathrm{INK} 4 \mathrm{a}}$ ) undergoes homozygous deletions and epigenetic silencing [11,12].

During the past two years, the first reports of whole-genome or exome sequencing data for HCC have appeared $[6,9,13]$. This is the beginning of a new era of HCC genetics, because of the fact that these new techniques will allow the visualisation of the mutational landscape of HCC. Figure 1 shows a summary of primary findings gathered by ourselves from two recently published reports $[6,9]$. Each study first analysed a small set of tumours $(n=20-25)$ for a genome-wide search of somatically mutated genes; significantly mutated genes were then further tested for mutations using a larger set of tumours $(n>100)$.

A close examination of the data of Fig. 1 indicates that TP53 and CTNNB1 represent the two most frequently mutated genes. A second group of genes (AXIN1 and ARID1A) was found to present less frequent mutations, but still present in more than $10 \%$ of HCC samples studied. The third group is the largest with 22 genes displaying recurrent mutations in less than $10 \%$ of tumours. Guichard et al. [6] reported that Wnt/ $\beta$-catenin, p53, PI3K/Ras signalling, oxidative, endoplasmic reticulum stress pathways and chromatin remodelling were frequently affected by these mutations.

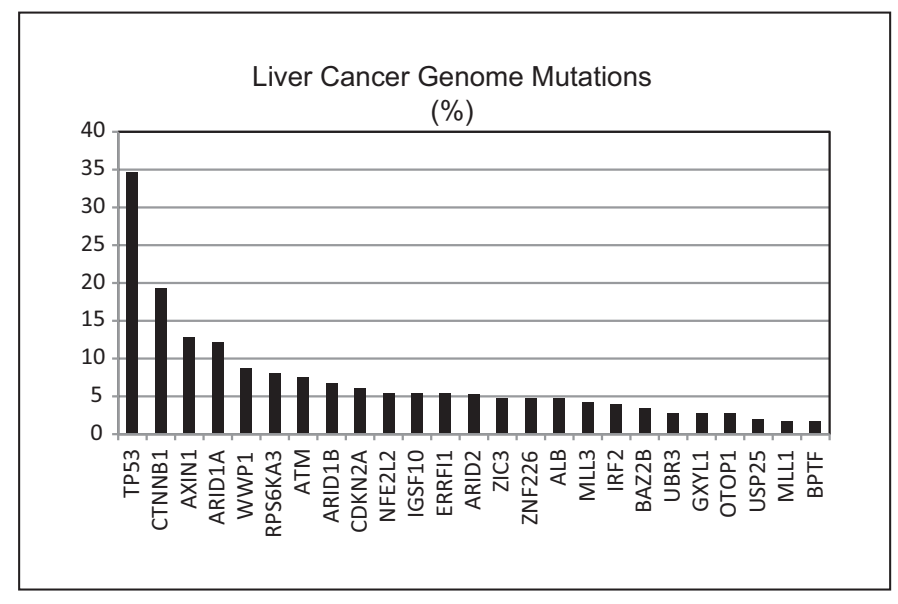

FIGURE 1

Most frequently mutated genes in hepatocellular carcinoma.

Whole genome sequencing allowed the detection of recurrent somatic mutations in several genes annotated as associated with chromatin regulation, such as ARID1A, ARID1B, ARID2, MLL, MLL3, BAZ2B, BRD8, BPTF, BRE and HIST1H4B. Notably, 14 out of the 27 tumours (52\%) had either somatic point mutations or indels in at least one of these chromatin regulators. In both sets of experiments (whole genome sequencing and the validation sets), the number of indels in chromatin regulator genes was significantly higher than those in genes belonging to the other categories. This suggests that loss-of-function mutations are enriched in these chromatin-regulator genes in HCC genomes [9].

As shown in Table 1, the frequent mutations that identified so far in HCC are likely to result in loss of function with the notable exception of CTNNB1 mutations. It will be interesting to study why loss of function rather than gain of function of crucial genes is associated with HCC. By contrast, this pattern of mutation does not offer a broad spectrum of therapeutic intervention applications. Cancer cells can easily be targeted by blocking genes that are aberrantly overactive in these cells. The restoration of a lost gene activity to achieve a therapeutic intervention is difficult to achieve. Thus, although the genome-wide analyses have been very helpful in establishing the list of a large set of mutated genes in HCC, this will most probably serve diagnostic needs while the chance of their therapeutic use is more limited.

\section{Epigenetic deregulation}

Epigenetic regulation of gene expression involves DNA methylation, post-translational histone modifications, chromatin changes and non-coding RNAs that are often affected in cancer cells [14,15]. The role of epigenetic deregulation in HCC is being increasingly recognised [16]. In addition to changes in DNA methylation, microRNA expression, mutations affecting epigenetic regulatory genes have recently been discovered in HCC $[6,9,13]$.

HCC cells display global hypomethylation as well as promoter hypermethylation of a large set of genes [17]. Promoter hypermethylation appears to affect mainly tumour suppressor and antiproliferative genes resulting in downregulation of gene expression (Fig. 2). Aberrations in microRNA expression have also been observed with several of them being linked to metabolic and phenotypic changes in HCC cells [14,18-20]. 
TABLE 1

Most frequent gene mutations in hepatocellular carcinoma are predicted to lead to a loss-of-function

\begin{tabular}{|c|c|c|c|}
\hline Genes & $\%$ mutation rates & Protein function & Known/expected outcome \\
\hline TP53 & 35 & DNA damage response, other & Loss-of-function \\
\hline CTNNB1 & 19 & Positive regulator of Wnt signalling & Gain-of-function \\
\hline AXIN1 & 13 & Negative regulator of Wnt signalling & Loss-of-function \\
\hline ARID1A & 12 & Chromatin remodelling & Loss-of-function \\
\hline WWP1 & 9 & E3 ubiquitin ligase & Loss-of-function? \\
\hline RPS6KA3 & 8 & Ribosomal protein S6 kinase & $?$ \\
\hline ATM & 8 & DNA damage response & Loss-of-function? \\
\hline ARID1B & 7 & Chromatin remodelling & Loss-of-function? \\
\hline CDKN2A & 6 & Positive regulator of senescence & Loss-of-function \\
\hline NFE2L2 & 5 & Redox homeostasis? & $?$ \\
\hline IGSF10 & 5 & $?$ & Loss-of-function \\
\hline ERRFI1 & 5 & EGFR/ERB2 kinase inhibitor & Loss-of-function \\
\hline ARID2 & 5 & Chromatin remodelling & Loss-of-function? \\
\hline
\end{tabular}

Several genes encoding epigenetic regulatory proteins are involved in hepatocellular malignancy. The EZH2 (KMT6) encodes the catalytic component of the Polycomb Repressive Complex 2 (PRC2), creating the transcriptionally repressive H2K27Me3 histone mark which results in transcriptional silencing [21]. EZH2 is over-expressed in HCC and mostly associated with the progression and aggressive biological behaviour of HCC $[22,23]$. EZH2 protein silences Wnt pathway antagonists and constitutively activates Wnt/ $\beta$-catenin signalling causing cell proliferation in HCC cells [24]. EZH2 also exerts a prometastatic function through epigenetic silencing of multiple tumour suppressor miRNAs including miR139-5p, miR-125b, miR-101, let-7c and miR-200b [25]. Yang et al. identified an lncRNA called lncRNA-HEIH (High Expression in HCC) that associates with EZH2 to repress EZH2 target genes such as $\mathrm{p} 16^{\text {Ink4a }}$ and $\mathrm{p} 21^{\mathrm{Cip} 1}$ in HBV-related HCC [26]. BMI1 is another PRC2 member overexpressed in HCC. Effendi et al. determined that BMI1 is upregulated in early and well-differentiated HCC and this expression correlates with ABCB1 expression [27].

Expression of histone deacetylases (HDACs) is deregulated in different cancers [28], and some of them are also deregulated in HCC. HDACs-1, -2 and -3 are over-expressed in HCC $[29,30]$. LC3B-II-induced inactivation of HDAC1 caused regression of HCC cell proliferation and triggered caspase independent autophagy. p21 ${ }^{\mathrm{Cip} 1}$ and $\mathrm{p} 2^{\mathrm{Kip} 1}$ were selectively induced while cyclin D1 and CDK2 were suppressed by inactivation of HDAC1. As a result, HDAC1 inactivation resulted in hypophosphorylation of $\mathrm{pRb}$ in the G1/S checkpoint to inactivate E2F/DP1 transcriptional activity. Also, p21 $1^{\text {(WAF1/Cip1) }}$ transcriptional activity was suppressed by

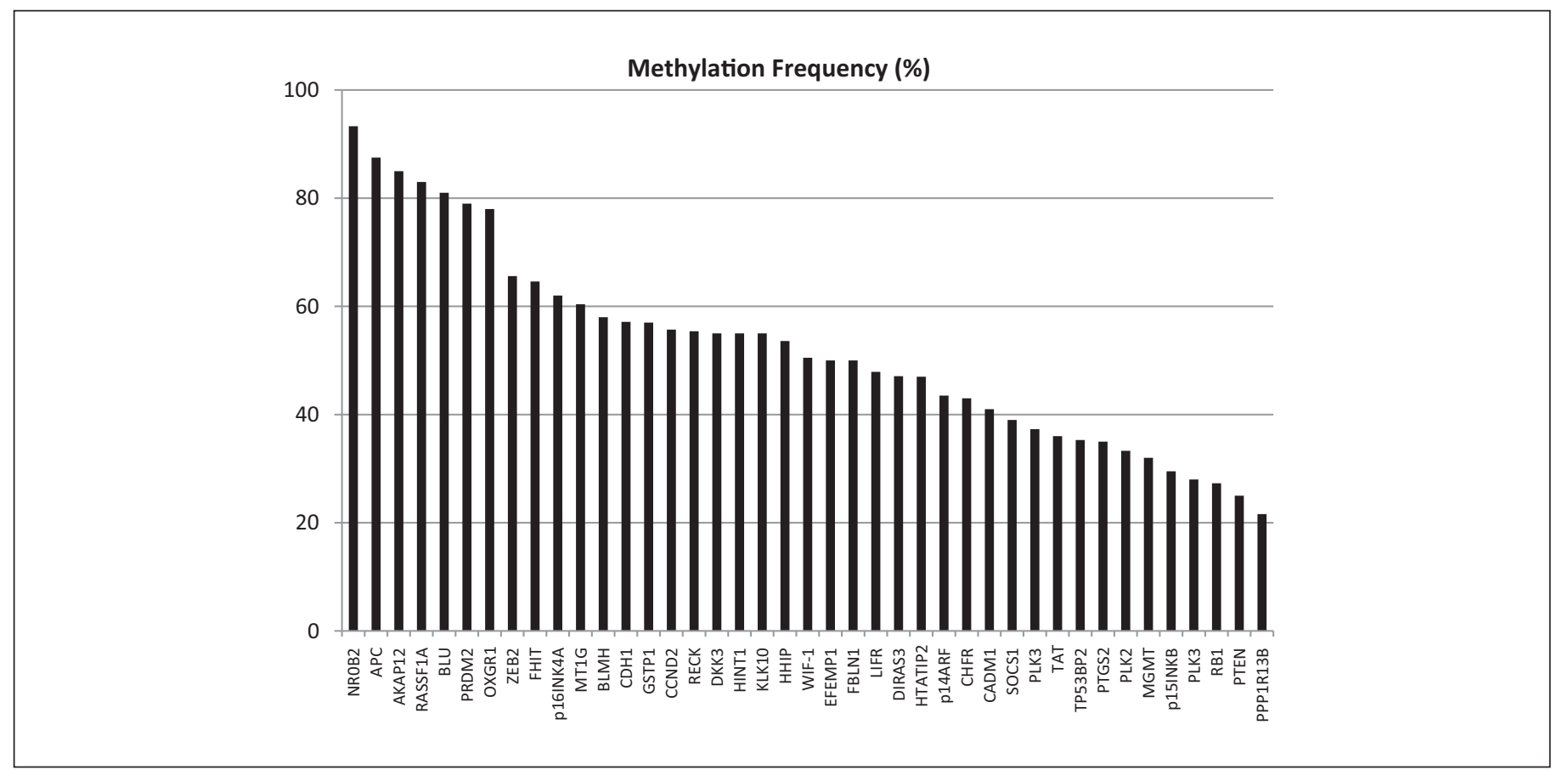


HDAC1by interaction with an Sp1-binding site in the p21 (WAF1/Cip1) promoter [31]. HDAC4 also suppresses the promoter activity of miR200a and its expression and interacts with Sp1 in the miR-200a promoter to attenuate histone H3 acetylation levels. miR-200a represses HDAC4 expression through targeting the 3 '-untranslated region of messenger RNA of HDAC4. In this respect, miR-200a has an ability to induce its own transcription and increase the levels of histone $\mathrm{H} 3$ acetylation at its promoter. Furthermore, miR-200a induces up-regulation of the levels of total acetyl-histone $\mathrm{H} 3$ and histone $\mathrm{H} 3$ acetylation in the $\mathrm{p} 21^{\mathrm{Cip} 1}$ promoter [32].

DNA methylating enzymes DNMT1, DNMT3A and DNMT3B are over-expressed in HCC compared to noncancerous liver samples $[33,34]$. Finally, CENPA expression was found to be significantly elevated in HCC tissues, and a positive correlation exists between CENP-A expression and $\mathrm{HBx} \mathrm{COOH}$ mutations in HCC tissues. HBx mutant increases the expression of CENPA mRNA [35].

\section{Future perspectives}

Recent advances in genome sequencing technologies will change radically our capabilities for fine mapping of hepatocellular cancer genomes. It is expected that patient tumours will be fully analysed in a short time at a moderate cost. Therefore, the genomic and epigenomic status of the patient's own tumour will be a crucial element for decision making in terms of disease prognosis, therapeutic choices and prediction of patient survival. However, most of the known mutations observed in HCC are associated with a loss of function. Apparently, targetable genes found in other cancers such as growth factor receptors and intracellular protein kinases are not mutated at significant levels in HCC. Therefore, we need to find other targets for the treatment of liver cancers. Epigenetic characterisation of HCC has allowed the discovery of many epigenetic players in this disease. However, these studies are far from being complete. The rarity of targetable mutations in HCC justifies a systematic study of epigenetic changes to identify new targets for the therapy of this disease.

\section{Acknowledgements}

The research study is supported by grants from TÜBİTAK (109S191 and 111T558) with additional support from State Planning Office (DPT-KANILTEK Project), Turkish Academy of Sciences, Institut National de Cancer and La Ligue Nationale Contre le Cancer in France (Equipe labelisée). C.O., G.Y. and D.C. received fellowships from Turkish Academy of Sciences (C.O.), TÜBİTAK (G.Y., D.C.) and EMBO (G.Y.).

\section{References}

[1] El-Serag HB. Hepatocellular carcinoma. New England Journal of Medicine 2011;365:1118-27.

[2] El-Serag HB. Epidemiology of viral hepatitis and hepatocellular carcinoma. Gastroenterology 2012;142:1264-1273.e1.

[3] El-Serag HB, Marrero JA, Rudolph L, Reddy KR. Diagnosis and treatment of hepatocellular carcinoma. Gastroenterology 2008;134:1752-63.

[4] Forner A, Llovet JM, Bruix J. Hepatocellular carcinoma. Lancet 2012;379:1245-55.

[5] Buendia MA. Genetic alterations in hepatoblastoma and hepatocellular carcinoma: common and distinctive aspects. Medical and Pediatric Oncology 2002;39:530-5.

[6] Guichard C, Amaddeo G, Imbeaud S, Ladeiro Y, Pelletier L, Maad IB, et al. Integrated analysis of somatic mutations and focal copy-number changes identifies key genes and pathways in hepatocellular carcinoma. Nature Genetics 2012;44:694-8.

[7] Brechot C, Pourcel C, Louise A, Rain B, Tiollais P. Presence of integrated hepatitis $B$ virus DNA sequences in cellular DNA of human hepatocellular carcinoma. Nature 1980;286:533-5.

[8] Brechot C, Gozuacik D, Murakami Y, Paterlini-Brechot P. Molecular bases for the development of hepatitis B virus (HBV)-related hepatocellular carcinoma (HCC). Seminars in Cell Biology 2000;10:211-31.

[9] Fujimoto A, Totoki Y, Abe T, Boroevich KA, Hosoda F, Nguyen HH, et al. Wholegenome sequencing of liver cancers identifies etiological influences on mutation patterns and recurrent mutations in chromatin regulators. Nature Genetics 2012;44:760-4.

[10] Bressac B, Galvin KM, Liang TJ, et al. Abnormal structure and expression of p53 gene in human hepatocellular carcinoma. Proceedings of the National Academy of Sciences of the United States of America 1990;87:1973-7.

[11] Ozturk M. Genetic aspects of hepatocellular carcinogenesis. Seminars in Live Disease 1999;19:235-42.

[12] Ozturk M, Arslan-Ergul A, Bagislar S, Senturk S, Yuzugullu H. Senescence and immortality in hepatocellular carcinoma. Cancer Letters 2009;286:103-13.

[13] Huang J, Deng Q, Wang Q, Li KY, Dai JH, Li N, et al. Exome sequencing of hepatitis B virus-associated hepatocellular carcinoma. Nature Genetics 2012;44:1117-21.

[14] Sandoval J, Esteller M. Cancer epigenomics: beyond genomics. Current Opinion in Genetics and Development 2012;22:50-5.

[15] Rodriguez-Paredes M, Esteller M. Cancer epigenetics reaches mainstream oncology. Nature Medicine 2011;17:330-9.

[16] Pogribny IP, Rusyn I. Role of epigenetic aberrations in the development and progression of human hepatocellular carcinoma. Cancer Letters 2012 [Epub ahead of print]

[17] Sceusi EL, Loose DS, Wray CJ. Clinical implications of DNA methylation in hepatocellular carcinoma. HPB (Oxford) 2011;13:369-76.

[18] Burchard J, Zhang C, Liu AM, Poon RT, Lee NP, Wong KF, et al. microRNA-122 as a regulator of mitochondrial metabolic gene network in hepatocellular carcinoma. Molecular Systems Biology 2010;6:402.

[19] Lachenmayer A, Alsinet C, Savic R, Cabellos L, Toffanin S, Hoshida Y, et al. Wntpathway activation in two molecular classes of hepatocellular carcinoma and experimental modulation by sorafenib. Clinical Cancer Research 2012;18:4997-5007.

[20] Murakami Y, Yasuda T, Saigo K, Urashima T, Toyoda H, Okanoue T, et al Comprehensive analysis of microRNA expression patterns in hepatocellular carcinoma and non-tumourous tissues. Oncogene 2006;25:2537-45.

[21] Cao R, Wang L, Wang H, Xia L, Xia L, Erdjument-Bromage H, Tempst P, et al Role of histone H3 lysine 27 methylation in Polycomb-group silencing. Science 2002;298:1039-43.

[22] Cai MY, Tong ZT, Zheng F, Liao YJ, Wang Y, Rao HL, et al. EZH2 protein: a promising immunomarker for the detection of hepatocellular carcinomas in liver needle biopsies. Gut 2011;60:967-76.

[23] Sasaki M, Ikeda H, Itatsu K, Yamaguchi J, Sawada S, Minato H, et al. The overexpression of polycomb group proteins Bmi1 and EZH2 is associated with the progression and aggressive biological behavior of hepatocellular carcinoma. Laboratory Investigation 2008;88:873-82.

[24] Cheng AS, Lau SS, Chen Y, Kondo Y, Li MS, Feng H, et al. EZH2-mediated concordant repression of Wnt antagonists promotes beta-catenin-dependent hepatocarcinogenesis. Cancer Research 2011;71:4028-39.

[25] Au SL, Wong CC, Lee JM, Fan DN, Tsang FH, Ng IO, et al. Enhancer of zeste homolog 2 epigenetically silences multiple tumour suppressor microRNAs to promote liver cancer metastasis. Hepatology 2012;56:622-31.

[26] Yang F, Zhang L, Huo XS, Yuan JH, Xu D, Yuan SX, et al. Long noncoding RNA high expression in hepatocellular carcinoma facilitates tumour growth through enhancer of zeste homolog 2 in humans. Hepatology 2011;54:1679-89.

[27] Effendi K, Mori T, Komuta M, Masugi Y, Du W, Sakamoto M. Bmi-1 gene is upregulated in early-stage hepatocellular carcinoma and correlates with ATPbinding cassette transporter B1 expression. Cancer Science 2010;101:666-72.

[28] Weichert W. HDAC expression and clinical prognosis in human malignancies. Cancer Letters 2009;280:168-76.

[29] Wu LM, Yang Z, Zhou L, Zhang F, Xie HY, Feng XW, et al. Identification of histone deacetylase 3 as a biomarker for tumour recurrence following liver transplantation in HBV-associated hepatocellular carcinoma. PLoS ONE 2010;5:e14460.

[30] Quint K, Agaimy A, Di Fazio P, Montalbano R, Steindorf C, Jung R, et al. Clinical significance of histone deacetylases $1,2,3$, and 7: HDAC2 is an independent predictor of survival in HCC. Virchows Archiv 2011;459:129-39.

[31] Xie HJ, Noh JH, Kim JK, Jung KH, Eun JW, Bae HJ, et al. HDAC1 inactivation induces mitotic defect and caspase-independent autophagic cell death in live cancer. PLoS ONE 2012;7:e34265.

[32] Yuan JH, Yang F, Chen BF, Lu Z, Huo XS, Zhou WP, et al. The histone deacetylase 4/SP1/microrna-200a regulatory network contributes to aberrant histone acetylation in hepatocellular carcinoma. Hepatology 2011;54:2025-35.

[33] Choi MS, Shim YH, Hwa JY, Lee SK, Ro JY, Kim JS, et al. Expression of DNA methyltransferases in multistep hepatocarcinogenesis. Human Pathology 2003;34:11-7.

[34] Saito $Y$, Kanai $Y$, Sakamoto $M$, Saito $H$, Ishii $H$, Hirohashi S. Expression of mRNA for DNA methyltransferases and methyl-CpG-binding proteins and DNA methylation status on CpG islands and pericentromeric satellite regions during human hepatocarcinogenesis. Hepatology 2001;33:561-8.

[35] Li Y, Zhu Z, Zhang S, Yu D, Yu H, Liu L, et al. ShRNA-targeted centromere protein A inhibits hepatocellular carcinoma growth. PLoS ONE 2011;6:e17794. 